\title{
VLF/LF Amplitude Perturbations before Tuscany Earthquakes, 2013
}

\author{
Balaram Khadka1,2, Keshav Prasad Kandel1,2, Sudikshya Pant1,2, Karan Bhatta1,2, \\ Basu Dev Ghimire ${ }^{1,2}$ \\ ${ }^{1}$ St. Xavier's College, Kathmandu, Nepal; ${ }^{2}$ Nepalese Center for Research in Physical Sciences (NCRPS), Kathmandu, \\ Nepal
}

Correspondence to: Balaram Khadka, keshavkandel5@gmail.com, suizpant123@gmail.com

Keywords: D-Layer, VLF/LF, Terminator Times, SST, SRT, DLPT, DLDT, Night Time Fluctuation

Received: October 14, 2017 Accepted: December 26, $2017 \quad$ Published: December 29, 2017

Copyright (๑) 2017 by authors and Scientific Research Publishing Inc.

This work is licensed under the Creative Commons Attribution International License (CC BY 4.0).

http://creativecommons.org/licenses/by/4.0/

\section{(c) (i) Open Access}

\section{ABSTRACT}

The US Navy VLF/LF Transmitter's NSY signal (45.9 kHz) transmitted from Niscemi, Sicily, Italy, and received at the Kiel Long Wave Monitor, Germany, was analyzed for the period of two months, May and June (EQ-month) of 2013. There were 12 earthquakes of magnitude greater than 4 that hit Italy in these two months, of which the earthquake of $21^{\text {st }}$ June having magnitude of 5.2 and a shallow focal depth of $5 \mathrm{~km}$ was the major one. We studied the earthquake of $21^{\text {st }}$ of June 2013, which struck Tuscany, Central Italy, $\left(44.1713^{\circ} \mathrm{N}\right.$ and $10.2082^{\circ} \mathrm{E}$ ) at $10: 33 \mathrm{UT}$, and also analyzed the effects of this earthquake on the sub-ionospheric VLF/LF signals. In addition, we also studied another earthquake, of magnitude 4.9, which hit the same place at 14:40 UT on $30^{\text {th }}$ of June and had shallow focal depth $10 \mathrm{~km}$. We assessed the data using terminator time (TT) method and night time fluctuation method and found unusual changes in VLF/LF amplitudes/phases. Analysis of trend, night time dispersion, and night time fluctuation was also carried and several anomalies were detected. Most ionospheric perturbations in these parameters were found in the month of June, from few days to few weeks prior to the earthquakes. Moreover, we filtered the possible effects due to geomagnetic storms, auroras, and solar activities using parameters like Dst index, AE index, and $\mathrm{Kp}$ index for analyzing the geomagnetic effects, and $\mathrm{Bz}$ (sigma) index, sunspot numbers, and solar index F10.7 for analyzing the solar activities for the confirmation of anomalies as precursors.

\section{INTRODUCTION}

Earthquakes still exist as a threatening disaster. Being able to predict earthquakes will certainly help prevent substantial loss of life and property. Perhaps, Very Low Frequency (VLF/LF) signals can be estab- 
lished as a tool to predict earthquake. VLF/LF band $(3-30 \mathrm{kHz})$ falls under radio spectrum and is widely known for its application in navigation and communication. Due to low attenuation and long wavelength, VLF/LF signals-transmitted from different VLF/LF transmitters established for research or other application purposes-can travel long distance by undergoing consecutive reflections between lower ionosphere and surface of the Earth. This system of ionosphere and earth that guides the VLF/LF wave is called Earth-ionosphere waveguide. Many research works present that perturbations in VLF/LF amplitudes or phases have been observed prior to earthquake day [1-4]. However, the results are often controversial for there are many other factors that might influence the VLF/LF waves. For instance, the ionospheric layer is highly influenced by geomagnetic winds, solar flares, cosmic rays and gamma-rays from the space, coronal mass ejection, so on and so forth, which can also bring about variations in VLF/LF wave propagation.

Anomalous shift in Terminator times, during sunrise and sunset, have been reported few days prior to earthquake day majorly in the works of [3,5-11]. Several studies show shifts in D-layer formation and D-layer disappearance time prior to seismic activities [12]. Extensive use of the methods of trend, dispersion and night time fluctuation have been done to analyze the VLF/LF signals, where the anomaly is characterized by the simultaneous decrease in the trend and the increases in dispersion and night time fluctuation [13-17]. Thus, changes observed in terminator times, trend, dispersion and night time fluctuation have been considered as precursor to earthquakes $[2,5,13-15,18,19]$. The analysis of the Central Italy Earthquake of 2016 was performed in our previous work for the same Transmitter-Receiver Great Circle Path (TRGCP) where significant anomalies in terminator times and night time data were found [14]. This work for Tuscany earthquake is an extension of previous work for earthquakes in Italy.

We carried out analysis of VLF/LF signals for the month of May and June (EQ month) 2013 to see if any perturbations occurred in those signals before the Tuscany earthquakes of $21^{\text {st }}$ of June of magnitude $5.2 \mathrm{M}$ and $30^{\text {th }}$ of June of magnitude $4.9 \mathrm{M}$. The earthquakes of magnitude $<5.5$ are considered incapable of perturbing the ionosphere. A long study had observed changes in VLF/LF signals only due to earthquakes that had magnitude at least greater than $5.5 \mathrm{M}$ [17]. However, in our Transmitter-Receiver Great Circle Path (TRGCP), we observed significant perturbations in VLF/LF amplitude despite having EQ of magnitude $<5.5 \mathrm{M}$ which makes our work an important one. Reference [16] had carried out similar research in finding the relation between earthquake and ionospheric perturbations using very long propagation path of length 11,400 km. The study was done on the earthquakes in the Indonesia region and anomalies due to an earthquake of magnitude 5.8, which had a depth of $53 \mathrm{~km}$ and epicenter $\sim 45 \mathrm{~km}$ away from the propagation path, were observed. Considerable deviation in terminator times and changes in the trend and night time fluctuation were reported. In contrast to [16], our propagation path was short with path distance

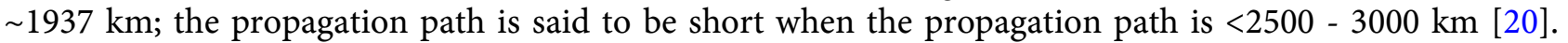
The earthquake on $21^{\text {st }}$ June 2013 (hereafter EQ-1) had shallow depth of $5 \mathrm{~km}$ while that of $30^{\text {th }}$ June 2013 (hereafter EQ-2) was $10 \mathrm{~km}$ and the propagation path almost crossed over the epicenters. Thus, we assume shallow depth of the earthquake to be the reason that the seismic activities could cause disturbances in the lower ionosphere. Similarly, these disturbances were received by the signal before they got attenuated due to the short propagation path length and closeness of epicenters to the propagation path; and hence, even the earthquakes of magnitude 5.2 and 4.9 could have caused considerable perturbations.

\section{TRANSMITTER AND RECEIVER}

The VLF/LF recording system of Kiel Long Wave monitor consists of a receiving antenna, a receiver antenna (amplifier), and a computer. The setup of Kiel Long Wave monitor consists of a Thin-Client computer along with identical ferrite loop antennae. The antenna runs at a constant location in a constant direction and nulls at 50 and 230 degrees. The receivers are broadband of $10-90 \mathrm{kHz}$ running 90 Fast Fourier Transforms (FFT) per second. Each datum used in this case was a one minute spectrum that was an average from approximately 5000 raw spectra. The Kiel Long wave Monitor records the VLF/LF spectrum between 10 and $96 \mathrm{kHz}$ by means of two receivers running at $6 \mathrm{~km}$ of distance: the $\mathrm{H}$-field probe $\left(54^{\circ} 23^{\prime} 46^{\prime \prime} \mathrm{N}, 10^{\circ} 03^{\prime} 13^{\prime \prime} \mathrm{E}\right)$ and the E-field $\left(54^{\circ} 22^{\prime} 24^{\prime \prime} \mathrm{N}, 10^{\circ} 08^{\prime} 15^{\prime \prime} \mathrm{E}\right)$. Figure 1 gives the outline of the procedures carried out in Kiel Long Wave Monitor. A total of 12 earthquakes greater than magnitude 4 in 


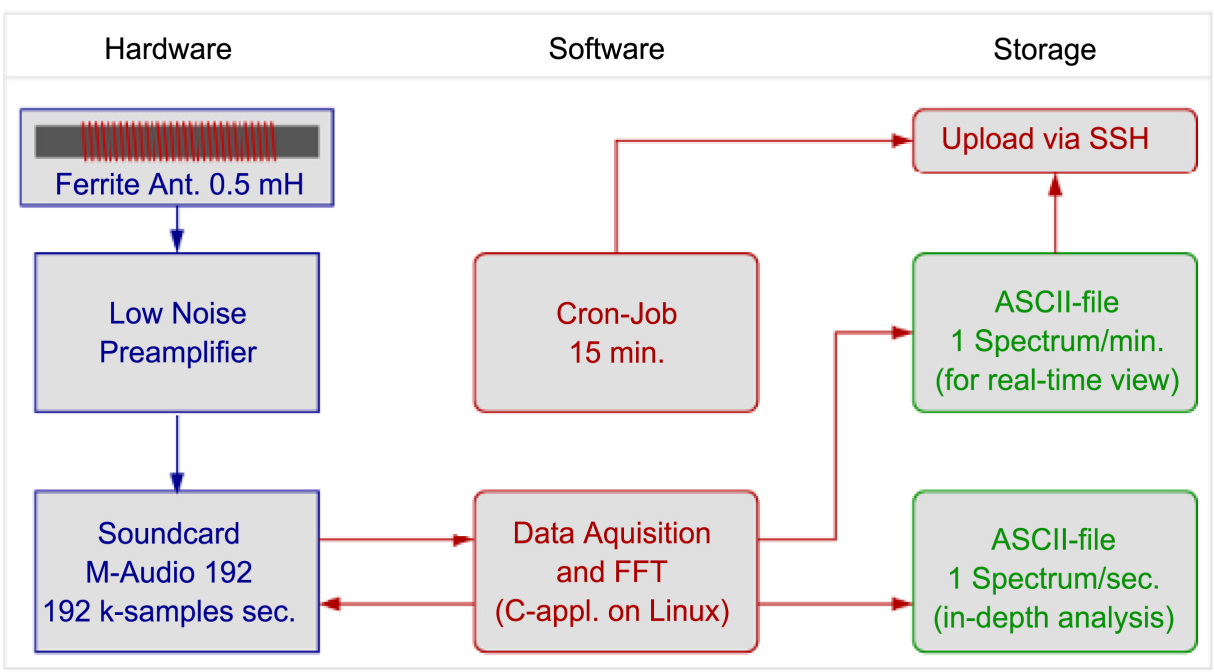

Figure 1. Block diagram of kiel long wave monitor where ferrite antennae receives the VLF/LF signals, amplifies, and processes them to obtain ASCII file finally containing minute average data and second average data. It uploads the data into web via SSH.

Table 1. Table showing earthquakes of magnitude greater than 4 in Richter scale in the month of May and June.

\begin{tabular}{cc}
\hline $\begin{array}{c}\text { Date of Occurrence } \\
\text { of Earthquake }\end{array}$ & $\begin{array}{c}\text { Magnitude of Earthquake } \\
\text { (Richter scale) }\end{array}$ \\
4 May 2013 & 4.1 \\
8 May 2013 & 4.1 \\
20 May 2013 & 4.0 \\
21 May 2013 & 4.5 \\
16 June 2013 & 4.1 \\
21 June 2013 & $4.1,4.5,5.2$ \\
23 June 2013 & $4.0,4.7$ \\
30 June 2013 & $4.7,4.9$ \\
\hline
\end{tabular}

Richter scale, struck Italy in the month of May and June as shown in Table 1 . However, we analyzed the effects of the Tuscany earthquake of $21^{\text {st }}$ June $2013(5.2 \mathrm{M})$ and $30^{\text {th }}$ June $(4.9 \mathrm{M})$, which were the two greatest earthquakes in these months, on NSY (North Somerset Yeomanry) signals transmitted from US Navy VLF/LF Transmitter of $45.9 \mathrm{kHz}$, Niscemi, Sicily, Central Italy (37.1N/14.4E) and received at the Kiel Long Wave Monitor. The Transmitter-Receiver Great Circle Path (TRGCP) is of $1949 \mathrm{~km}$, running almost completely over land.

\section{METHODS OF ANALYSIS}

Broadly, two method of analysis used are as follows:

1) Terminator time (TT) method;

2) Night time Fluctuation (NF) method. 
The terminator time method takes into account two parameters: Sunrise terminator time (SRT) and Sunset terminator time (SST). We observed one minimum for each morning and evening around sunrise and sunset. We will simply use SRT for sunrise terminator time and SST for sunset terminator time henceforth. SRT is defined as the first minimum which occurs after the sharp weakening of signals around sunrise and SST is defined as the last weakening of the signal before its sharp rise around sunset (marked by arrows in Figure 2) [12]. Moreover, we have marked $\mathrm{T}_{\mathrm{A}}$ to be time from which the signal starts to weaken sharply towards SRT (marked by arrows and dashed vertical blue lines) and $\mathrm{T}_{\mathrm{B}}$ to be time where signal becomes more or less constant after a period of sharp increase from SST (marked by arrows and dashed vertical green lines). The parameter SRT $-\mathrm{T}_{\mathrm{A}}$ (SRT minus $\mathrm{T}_{\mathrm{A}}$ ) is D-layer Preparation time (DLPT), time taken to lower D-layer boundary in the early morning and $\mathrm{T}_{B}-\mathrm{SST}\left(\mathrm{T}_{\mathrm{B}}\right.$ minus SST) is D-layer disappearance time (DLDT), time taken to raise D layer boundary again in the evening $[11,12]$. There are two other minima in between SRT and SST which are fluctuating rapidly and randomly throughout the month, due to solar effects.

There are two methods of nighttime fluctuation method. In method by [4], we calculate the difference between maximum and minimum fluctuations of signal amplitude during nighttime. In our case, the night time taken is 21:15 UT to 2:00 UT. We have plotted this difference for 19 days centered on $21^{\text {st }}$ June, EQ- 1 . In method by [13], we have computed various parameters namely trend, nighttime fluctuation and dispersion based on local nighttime. Here, the procedure to calculate $\pm 2 \sigma$ lines and to calculate trend and night time

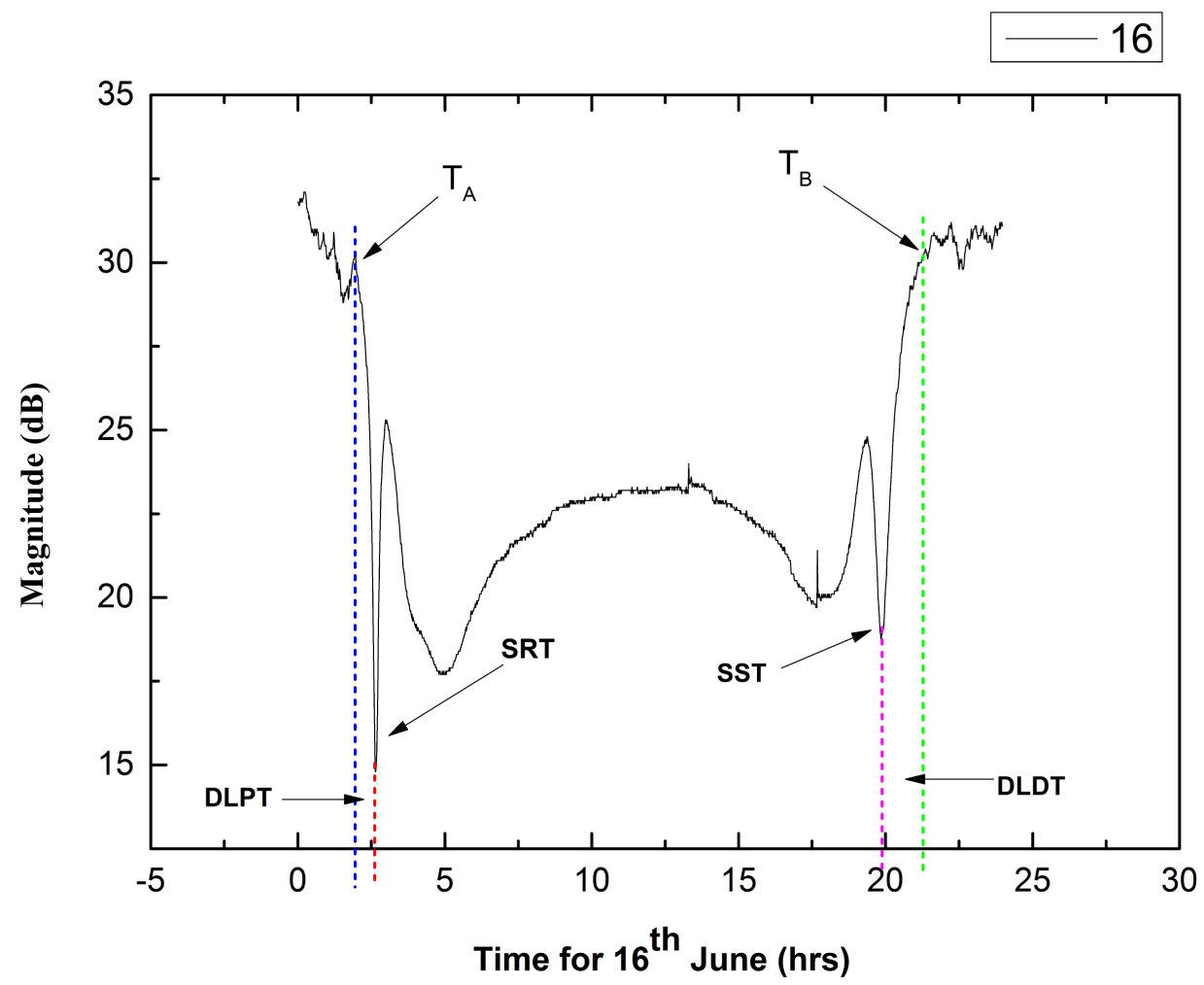

Figure 2. Variation of amplitude of VLF/LF signal on $16^{\text {th }}$ of June. The first minimum around sunrise is sunrise terminator time (SRT) and the second minimum around sunset is sunset terminator time (SST). D-layer preparation time (DLPT) is the time period between the blue and red dashed lines and D-layer disappearance time (DLDT) is the time period between the pink and green dashed lines. $T_{A}$ and $T_{B}$ are the points where blue and green lines intersect the graph respectively. 
fluctuation is escaped as it has been explained thoroughly in our previous work [14]. However, we have mentioned the formulas that we used and discussed about new a parameter being used in this paper.

Considering initial terminator times as $T_{i}$ and final terminator time as $T_{f}$ trend, night time dispersion, and night time fluctuations can be mathematically calculated as:

$$
\begin{gathered}
\text { Trend }=\frac{\int_{T_{i}}^{T_{f}} d A d t}{T_{f}-T_{i}} . \\
\text { Dispersion }{ }^{*}=\frac{\int_{T_{i}}^{T_{f}} d A^{*} d t}{T_{f}-T_{i}} . \\
\text { Nighttime Fluctuation }(\mathrm{NF})=\frac{\int_{T_{i}}^{T_{f}} T_{i} A^{2} d t}{T_{f}-T_{i}} ; d A<0 .
\end{gathered}
$$

where,

$d A=A_{\text {time }}-\left\langle A_{\text {mon }}\right\rangle=$ deviation of instantaneous amplitude from monthly average (at the same time).

$d A^{*}=A_{\text {time }}-\left\langle A_{\text {night }}\right\rangle=$ deviation from night time average (night of particular date).

Here, integration represents the area under the curve $d A$ over time $(d t)$ which is further divided by the interval between the chosen terminator times $\left(T_{f}-T_{i}\right)$.

The parameter night time dispersion is the variation from the night time average of amplitudes $\left(\left\langle A_{\text {night }}\right\rangle\right)$. Night time dispersion considers deviation from night time average rather than deviation from daily average. We couldn't calculate the daily averages because we had poor daytime data (owing to transmitter shutdowns). So, we simply used the night time data we had in order to find night time averages and eventually calculated the deviations from those night time averages. This new parameter was then called night time dispersion, denoted as dispersion*. This parameter would measure how the night time data is fluctuating from the average of the particular night. We expect this parameter, dispersion ${ }^{\star}$, to decrease simultaneously with anomalies in trend and night time fluctuation because significant decrease in amplitude has been found to be signature of seismic activities [2,17].

The terminator times and nighttime amplitudes are supposed to be more or less constant on normal days, days unaffected by solar and geomagnetic activities, lightning, CG Flashes, LAIC and so on. The data points must lie closely around the line of best fit. Standard deviation, represented by $\sigma$, is a measure of how far the data points are deviated over whole set of data, implying a state where all data points vary between $\pm \sigma$ lines. However, if data crosses $\pm \sigma$ lines, it indicates that the ionosphere is perturbed to some extent by various events like solar and geomagnetic activities. On crossing $\pm 2 \sigma$ lines, it indicates a significant perturbation caused in ionosphere. It is believed that the deposition of ground seismic energy or radioactive decay of radon and other isotopes into the ionosphere can cause excessive ionization which may enhance the conductivities of these regions much before the seismic event [21]. The heating by radon decay may also produce slow expansion of atmosphere which can perturb the ionosphere. Moreover, fracturing of tectonic plate emits ions and electron to affect the conductivity of the ionosphere. However, real physical explanation is least understood due to less progress in lithosphere-ionosphere coupling. This way, the ionosphere is perturbed strongly from few days to few weeks before the earthquake day causing the data of various parameters to shift crossing $\pm 2 \sigma$ lines.

\section{RESULTS}

\subsection{Terminator Time (TT) Method}

This is the first method of data analysis in which we plotted the graphs of sunrise terminator time 
(SRT) and sunset terminator time (SST) against days for the month of May and June 2013. The each graph possess three colored lines, the upper green line with small triangles which represents $+2 \sigma$ line, the middle red line with small circles indicating the trend line (the line of best fit), and lastly the lower blue line with small triangles which symbolizes $-2 \sigma$ line. The values that cross the green line $(+2 \sigma$ line) or blue line $(-2 \sigma$ line) are considered "anomalous values".

In the month of May, the month prior to earthquake month, we found SRT well within $\pm 2 \sigma$ lines (the green and blue lines) as shown in the Figure 3(a). Similarly, it can be seen in Figure 3(b) that SST shows shift on $3^{\text {rd }}$ of May 2013 as it crosses $-2 \sigma$ line (the blue line). D-layer preparation time (DLPT)does not show abnormality but D-layer disappearance time (DLDT) was found to cross $2 \sigma$ line (lower blue line) on $3^{\text {rd }}$ of May as presented in Figure 4. This anomaly in DLDT on $3^{\text {rd }}$ May couldn't be the precursor to the earthquake of June $21^{\text {st }}$ and $30^{\text {th }}$ which were still 48 - 57 days away. However, the shift in $3^{\text {rd }}$ of May could be the precursor to the earthquake of $4^{\text {th }}$ of May of magnitude 4.1 (and even due to the effects of other earthquakes like that of 8 May having magnitude 4.4). It can't be ignored that the earthquakes given in Table 1 have very shallow depth varying from $4 \mathrm{~km}$ to $10 \mathrm{~km}$; and Tuscany is an area that falls almost within the propagation path of the signals i.e., the VLF/LF NSY signals from Niscemi nearly passes over Tuscany on the way to Kiel, Germany, where the signal are received. Thus, the shallow depth could be the reason that the weak earthquakes of magnitude just as great as 4 could cause disturbances and were easily detected. And the solar activities were also relatively high on $3^{\text {rd }}$ May as shown by the increase in solar
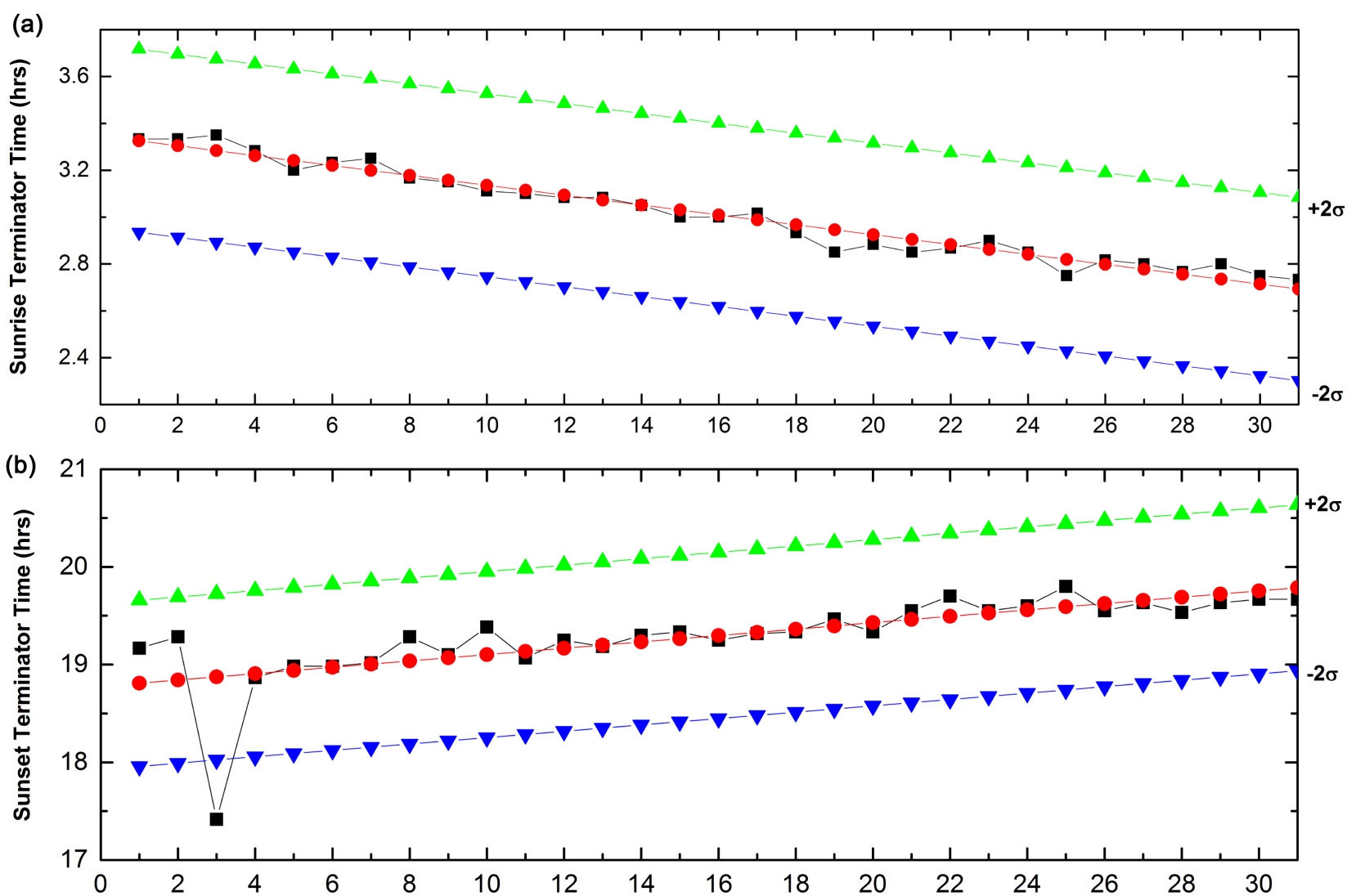

Days for the Month of May, 2013 AD

Figure 3. (a) Daily variation in sunrise terminator time (SRT) for the month of May (b) Daily variation in sunset terminator time (SST) for the month of May. The upper green line signifies $+2 \sigma$ line, the middle red line represents trend line (line of best fit), and the lower blue line symbolizes the $-2 \sigma$ line. SST shifted on $3^{\text {rd }}$ of May and crossed $-2 \sigma$ line (lower blue line). 

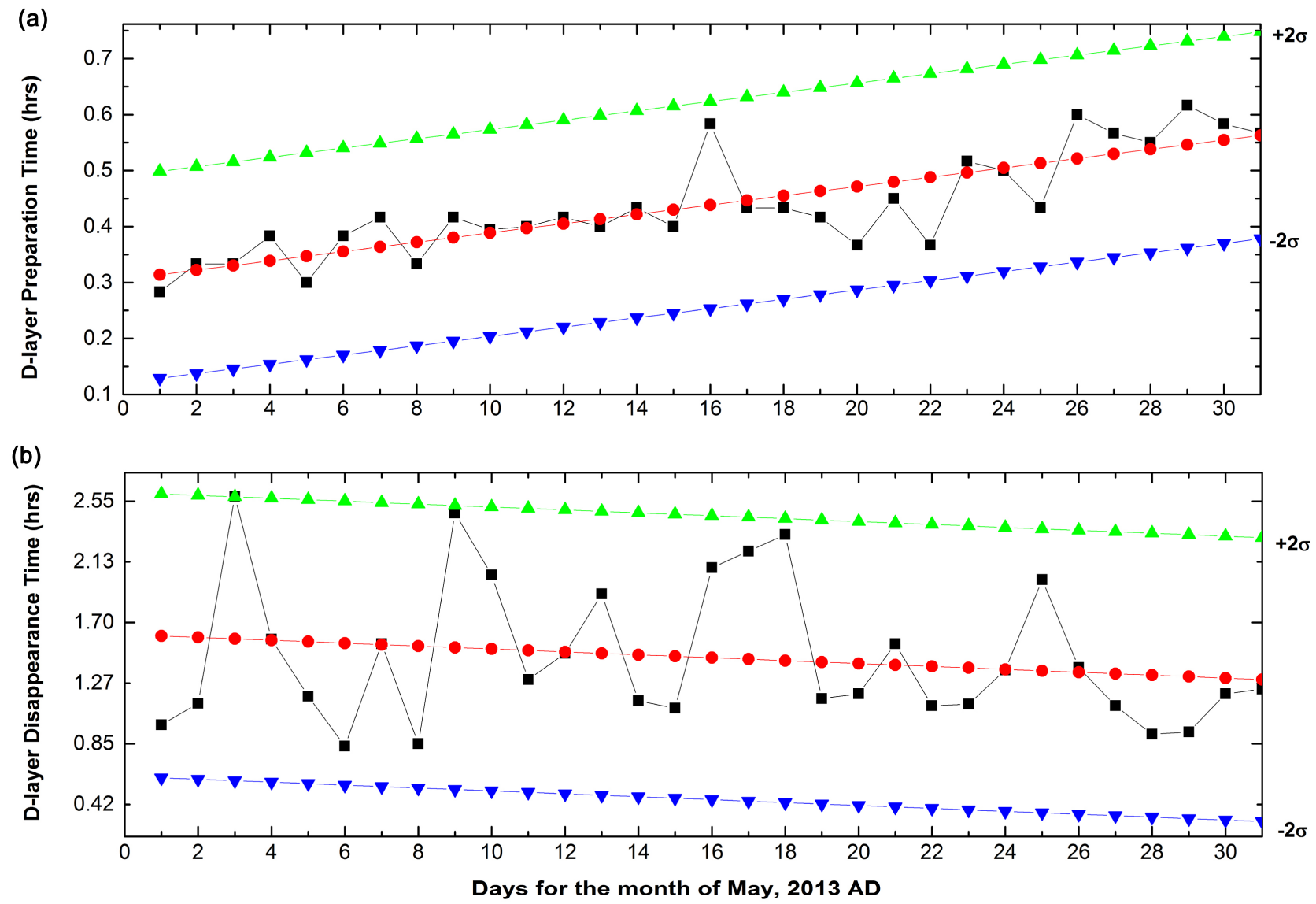

Figure 4. (a) Daily variation in D-layer preparation time (DLPT) for the month of May (b) Daily variation in D-layer disappearance time (DLDT) for the month. The upper green line signifies $+2 \sigma$ line, the middle red line represents trend line (line of best fit), and the lower blue line symbolizes the $-2 \sigma$ line. On $3^{\text {rd }}$ of May, DLDT just crossed $2 \sigma$ line (upper green line).

F10.7 index. The effects of solar and geomagnetic activities will be dealt again in the section 5 in more detailed way. Thus, it is also likely that the anomaly was caused due to the effect of earthquakes (occurring in the month of May) as well as that of solar activities.

In the month of June (EQ-month), greater perturbations in the VLF/LF amplitudes were observed. The sunrise terminator time (SRT) shifted toward the night as it crossed $-2 \sigma$ line (lower blue line) on $23^{\text {rd }}$ of June, 7 days prior toEQ-2, as seen in Figure 5(a). The SRT greatly shift towards the night on $7^{\text {th }}, 8^{\text {th }}$ and $18^{\text {th }}$ June (days before EQ-1) though does not cross the $2 \sigma$ lines. The sunset terminator time SST crossed the $\pm 2 \sigma$ lines on $1^{\text {st }}, 7^{\text {th }}, 9^{\text {th }}, 11^{\text {th }}, 13^{\text {th }}, 17^{\text {th }}, 18^{\text {th }}, 21^{\text {st }}, 22^{\text {nd }}, 23^{\text {rd }}, 24^{\text {th }}$ and $27^{\text {th }}$ of June, as presented in Figure 5(b). However, the entire anomalous shifts might not have been the effect of just EQ-1 and EQ-2. The shift in SST on $1^{\text {st }}, 7^{\text {th }}, 9^{\text {th }}, 11^{\text {th }}$, and $13^{\text {th }}$ might have occurred due to earthquake of 16 June 2013 which had magnitude of 4.1 and epicenter $\sim 98 \mathrm{~km}$ away from the propagation path. It had shallow depth as well i.e., $<10$ $\mathrm{km}$. And the anomalies on $17^{\text {th }}$ and $18^{\text {th }}$ June might have been due to the seismic activities that might have disturbed the lower ionosphere before the tremor was felt on $21^{\text {st }}$ June (5.2 M, EQ-1). Similarly, the shift of SST on $21^{\text {st }}$ and $22^{\text {nd }}$ could be precursor to the earthquake of $23^{\text {rd }}$ of June $(4.7 \mathrm{M}$ and $4.0 \mathrm{M})$ and that of $23^{\text {rd }}$, $24^{\text {th }}$, and $27^{\text {th }}$ might be precursor to earthquake of $30^{\text {th }}$ June (4.7 M and 4.9 M, EQ-2). These results are consistent with our claim that changes in terminator times are seen before earthquakes. Focusing on the main earthquakes under study, we find that anomalies were seen from 3 days $\left(18^{\text {th }}\right.$ June) to 4 days $\left(17^{\text {th }}\right.$ June) prior to EQ-1 and 7 days ( $23^{\text {rd }}$ June) to 3 days ( $27^{\text {th }}$ June) prior to EQ-2. However, these aren't filtered data. 
(a)

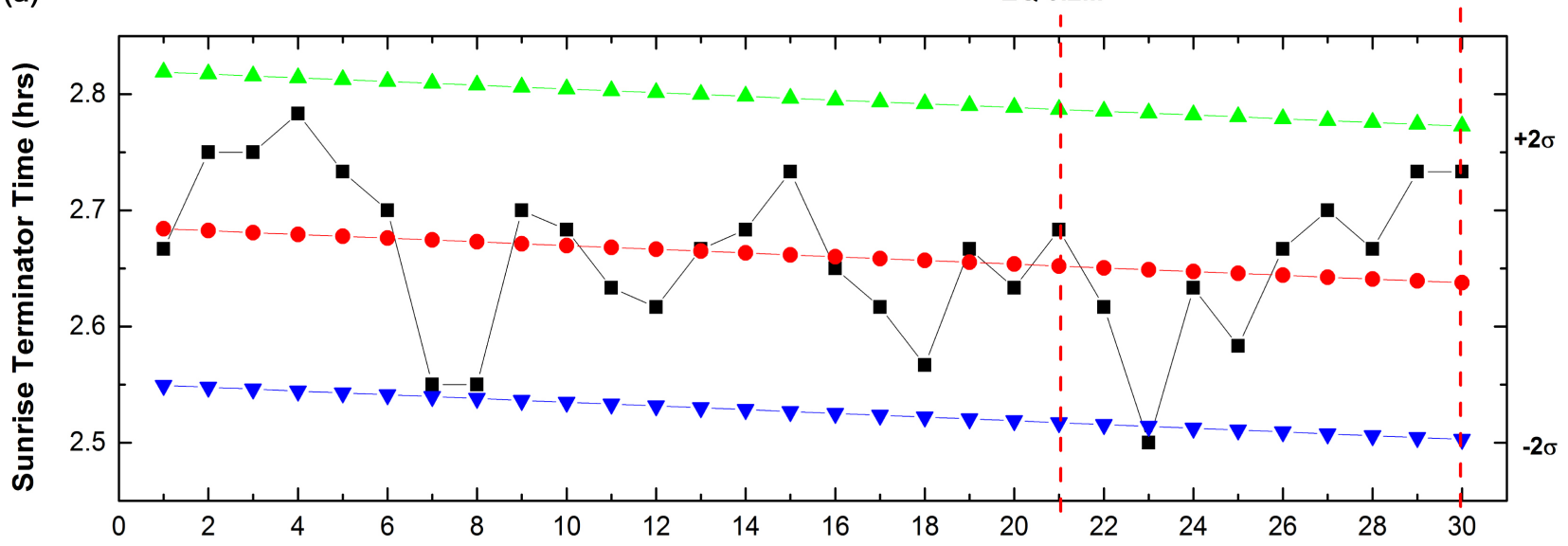

(b)

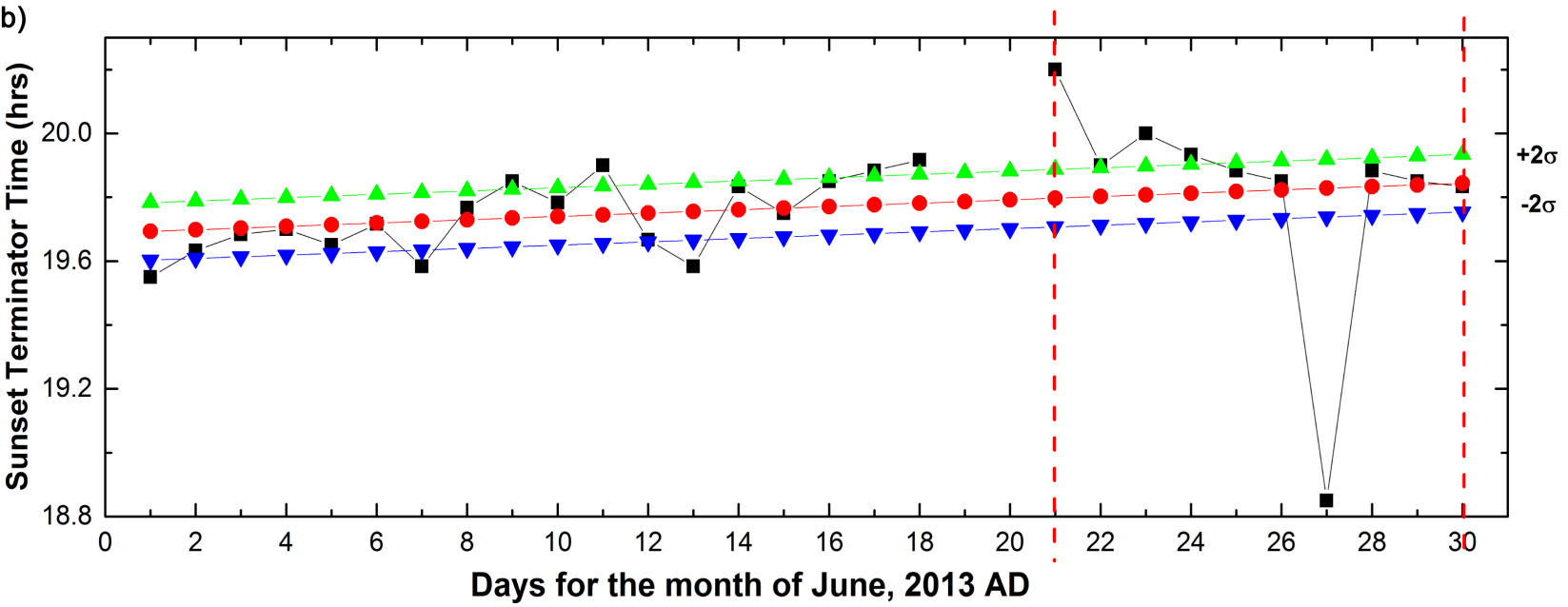

Figure 5. (a) Daily variation in sunrise terminator times (SRT) for the month of June (b) Daily variations in sunset terminator times (SST) for the month of June. The upper green line signifies $+2 \sigma$ line, the middle red line represents trend line (line of best fit), and the lower blue line symbolizes the $-2 \sigma$ line. The red dashed lines marks the earthquake days of $21^{\text {st }}$ June and $30^{\text {th }}$ June.

However, the conclusion section provides a table where the summary of probable precursors after casting out the days that were influenced by solar or geomagnetic activities.

It was unusual not to get any anomalies before the earthquake of $21^{\text {st }}$ May of magnitude 4.5 (greater than that of $4^{\text {th }}$ and $5^{\text {th }}$ May or $16^{\text {th }}$ June). It was also surprising to find such a great shift on $27^{\text {th }}$ of June. On evaluating the geomagnetic and solar activities, no significant changes in the parameters were found on $27^{\text {th }}$ of June except for $\mathrm{Bz}$ (sigma), which seemed relatively higher. Thus, the anomaly might have resulted from combined effect of the earthquakes-of magnitude 4.7 and 4.9 that struck Tuscany on $30^{\text {th }}$ June- and solar activities. Most of our results agreed that anomalous shift in terminator times could be considered possible precursors of the earthquakes. From the Figure 6(a), we can observe that D-layer preparation time (DLPT) shows anomaly 5 days before EQ- 2 as it just crosses the $+2 \sigma$ lines (upper green lines in graph) on $25^{\text {th }}$ of June while D-layer disappearance time (DLDT) shows anomaly 11 days before of EQ-1 and 2 days before EQ-2 for it just touches the $\pm 2 \sigma$ on $10^{\text {th }}$ and $28^{\text {th }}$ of June 2013. However, we didn't observe any anomalous fluctuations in value of DLPT before EQ-1.

On the basis of these results for the month of June, it is clear that perturbations were seen in terminator time before the Tuscany EQ-1 and EQ-2. Thus, perturbations in the terminator times are likely to be 

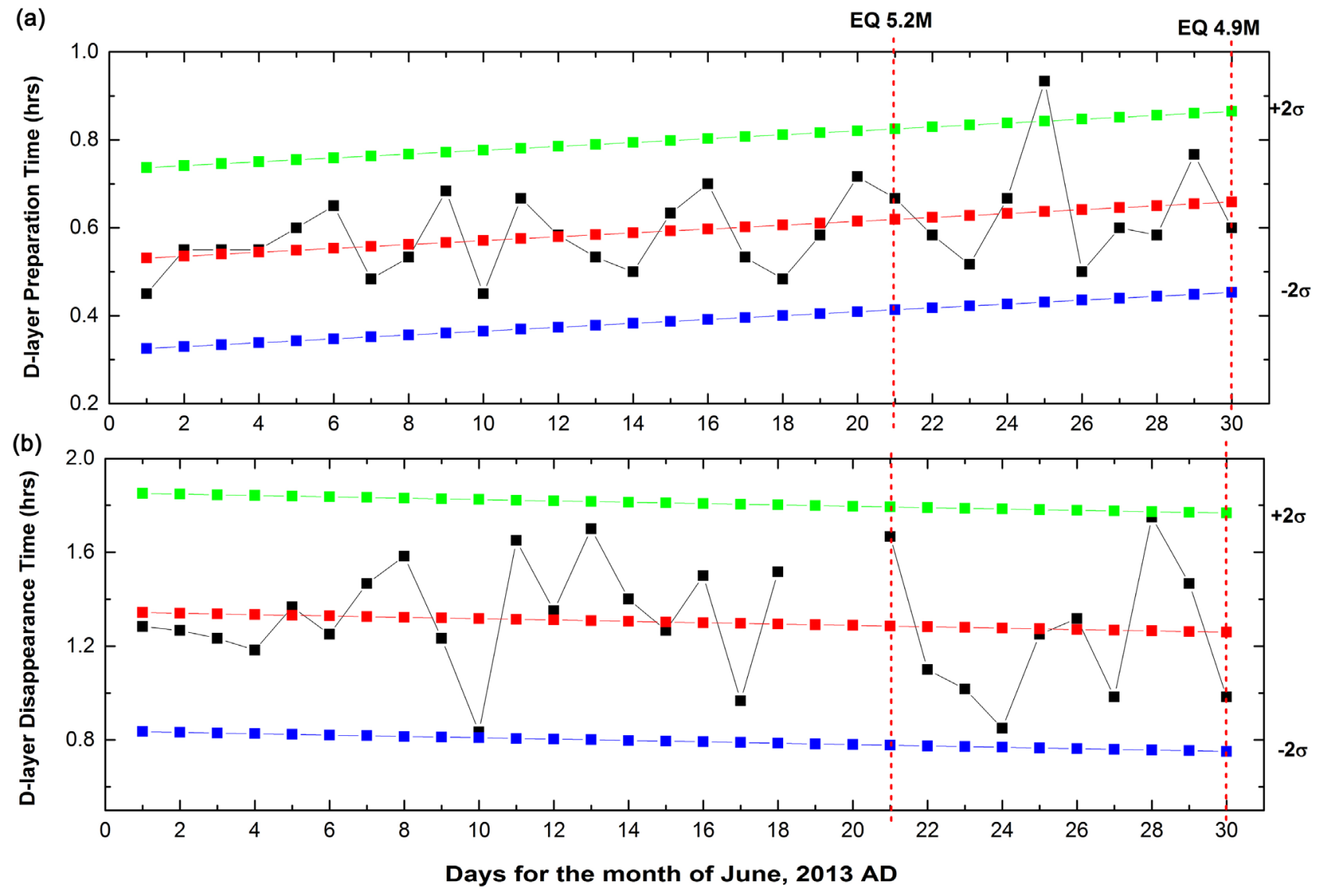

Figure 6. (a) Daily variation in D-layer preparation time (DLPT) for the month of June (b) Daily variation in D-layer disappearance time (DLDT) for the month of June. The upper green line signifies $+2 \sigma$ line, the middle red line represents trend line (line of best fit), and the lower blue line symbolizes the $-2 \sigma$ line. The red dashed lines marks the earthquake days of $21^{\text {st }} J$ une and $30^{\text {th }}$ June.

observed before the earthquake which can help in predicting it. Similarly, DLPT and DLDT also show perturbations before earthquake and can be considered as a precursor to the earthquake.

\subsection{Nighttime Fluctuation (NF) Method}

In Figure 7, we plot the absolute difference between maximum amplitude signal and minimum amplitude signal of particular night over 19 days centered to EQ-1. We computed data based on each night's data as in [4]. We noted that the peak occurs anomalously 2 days before the event implying that the fluctuation becomes very high. In Figure 7(a), the dashed line represents the average nighttime amplitude fluctuation and the short dotted line represents the $+3 \sigma$ line (where $\sigma$ is the standard deviation), computed on each night. The red vertical dashed line shows the day of earthquake (EQ-1, 5.2 M). Clearly, the graphs in Figure 7(a) shows that the fluctuations peak crossed $+3 \sigma$ line on 19th of June, two days prior to EQ-1. Interestingly, the day 19th June was international quiet day (see Section 6) i.e. geomagnetic variations were quite low, which strengthens the fact that anomalies were there as a precursor. This is consistent with previous findings by the authors [4]. However no such fluctuation peak was observed before the EQ-2 implying less perturbation during nighttime.

\subsection{Trend, Night Time Fluctuation, and Night Time Dispersion}

In night time fluctuation method, we estimated the values of trend and night time fluctuation to show 

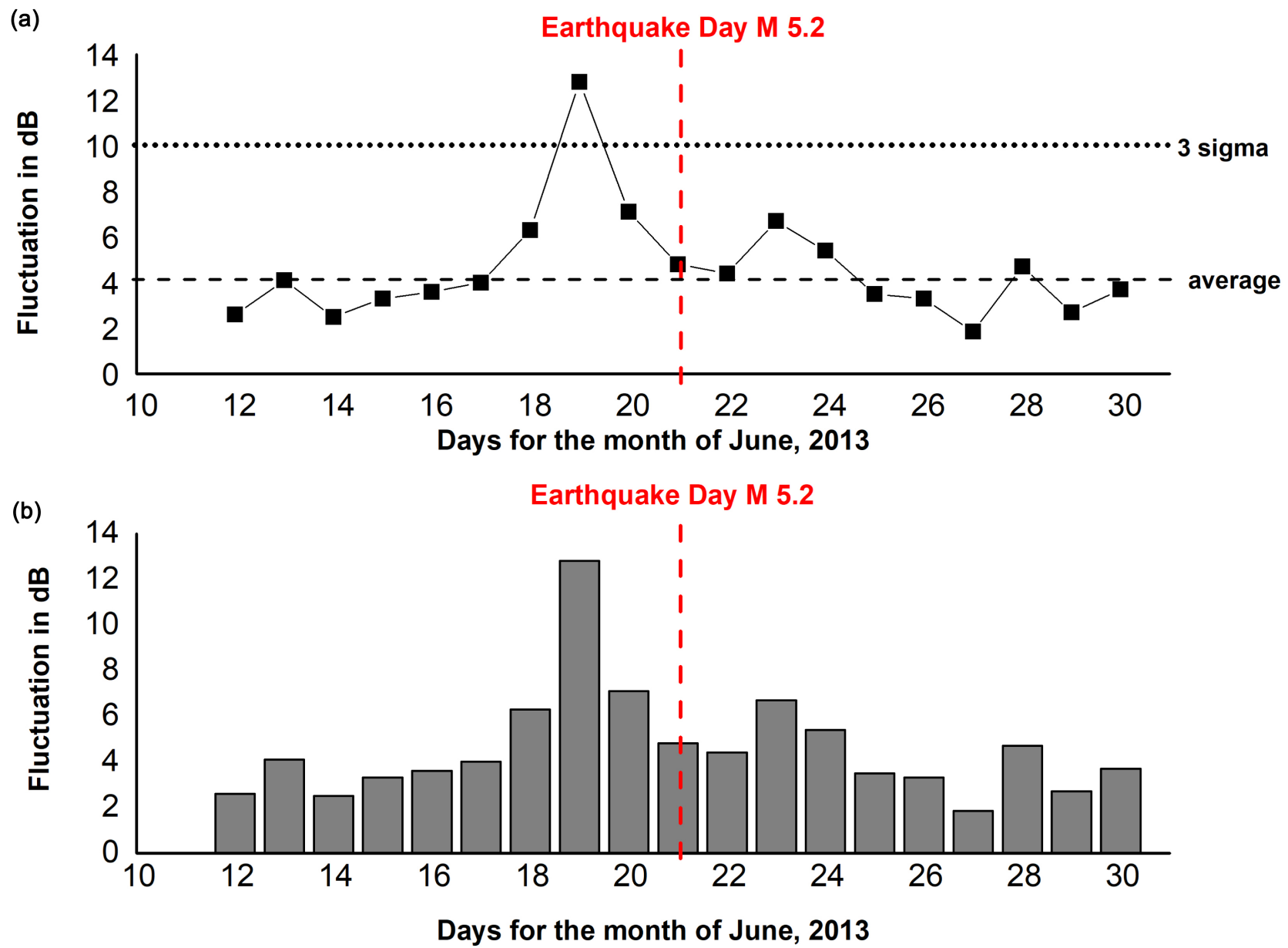

Figure 7. (a) The amplitude of the nighttime VLF fluctuations (closed squares) signals are plotted as a function of day number. The horizontal dashed line represents the average nighttime fluctuations while the horizontal short dotted line represent the $+3 \sigma$ line. The vertical red dashed line indicates EQ-1. The fluctuation 2 days before the event crossed the $+3 \sigma$ line; (b) The nighttime VLF amplitude fluctuations for 19 days centered on earthquake of $21^{\text {st }}$ June 2013. The peak appears 2 days before the event.

that both of these parameters show unusual behavior simultaneously prior to the earthquake as described in $[13,15-17]$ and we expect the night time fluctuation to cross the $2 \sigma$ lines (i.e. to show anomaly) with simultaneous decrease in trend and increase in dispersion. However, in case of the dispersion, instead of taking the daily averages we only took the night time averages and determined the value for night time dispersion (dispersion ${ }^{\star}$ ). Therefore, in our case, we expect the dispersion ${ }^{\star}$ to decrease simultaneously on the days when trend and night time fluctuation cross $2 \sigma$ lines. These parameters have been explained in Section 3. Figure 8 shows non-normalized trend, night time dispersion, and night time fluctuations, while Figure 9 shows the normalized trend, night time fluctuations and night time dispersion for the month of May and June. For obtaining values for normalized trend, we subtract the average of month from the trend of corresponding days and then, divide it by their standard deviation. In the same way, we compute normalised night time dispersion and normalised night time fluctuation. In normalized graphs, it automatically brings in sigma lines, making analysis easier.

The anomalous values, the values that cross $2 \sigma$ line (horizontal dashed line), are denoted by red filled columns in corresponding graphs in Figure 8 and Figure 9. The trend value declined and crossed the $2 \sigma$ line 


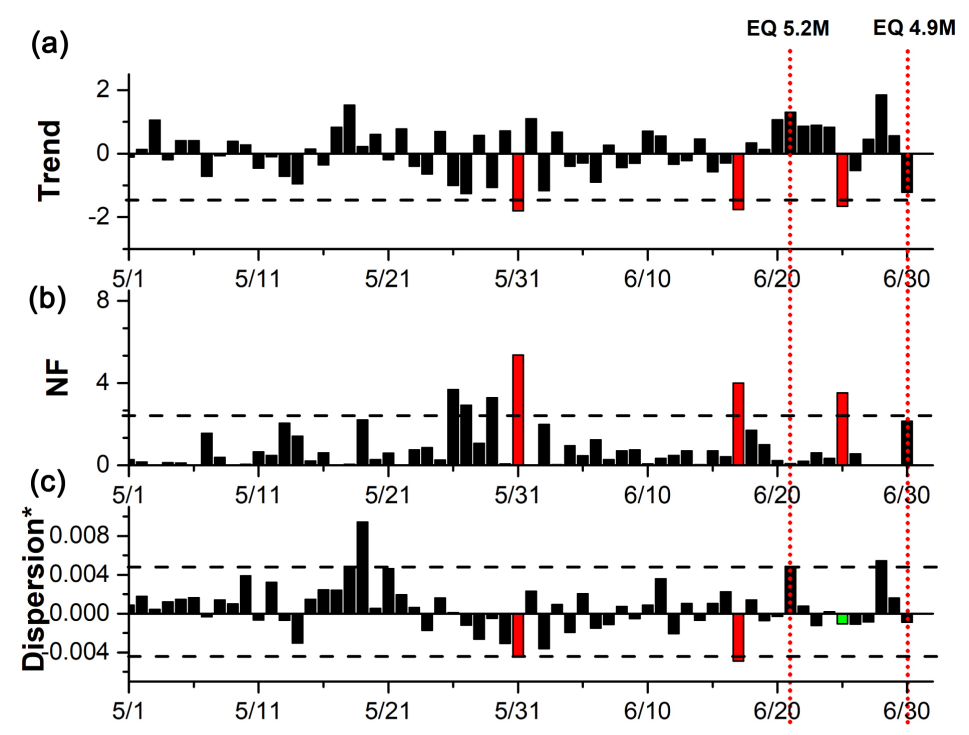

Days for the month of May and June, 2013

Figure 8. Graphical representations of non-normalized trend, night time fluctuation (NF), and night time dispersion. The horizontal black dashed lines represent the $\pm 2 \sigma$ lines. The red filled columns represent anomalous values (values crossing the $2 \sigma$ lines) while the green filled column in dispersion* $(8(c))$ indicates unusual value relative to the trend and night time fluctuation on $25^{\text {th }}$ June. The earthquakes on $21^{\text {st }}$ June and $30^{\text {th }}$ June are marked by vertical red dashed lines.

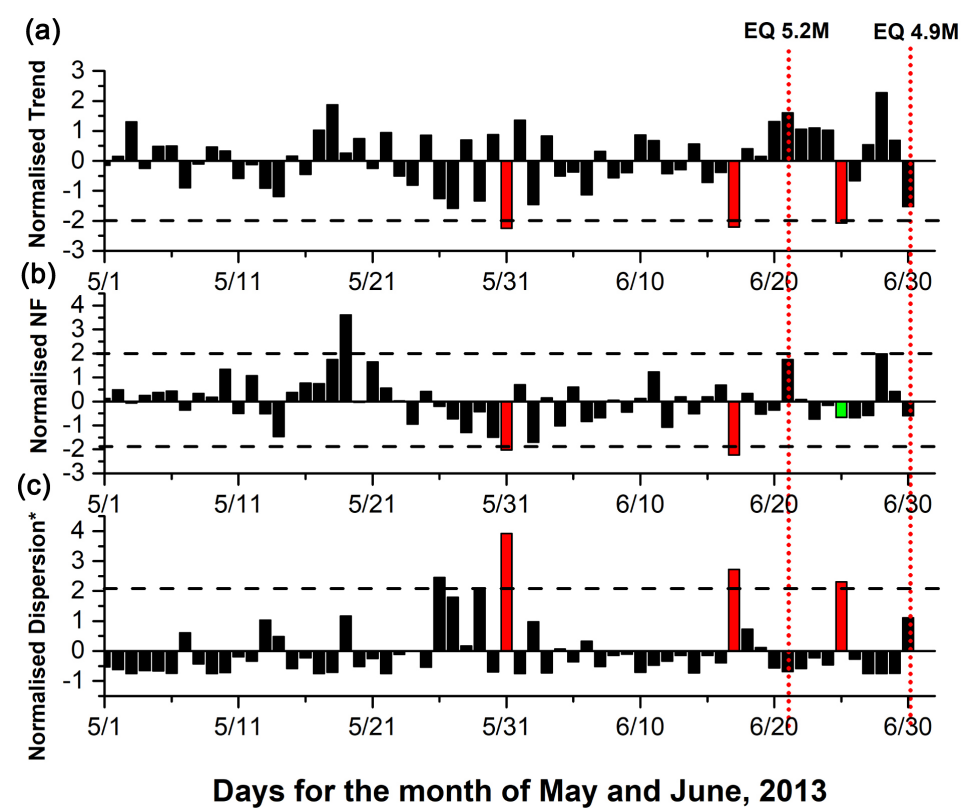

Figure 9. Graphical representation of normalized trend, night time fluctuation (NF), and dispersion. The horizontal black dashed lines represent the $\pm 2 \sigma$ lines. The red filled columns represent anomalous values (crossing the $2 \sigma$ lines) while the green filled column in normalized night time fluctuation, Figure 10(b), indicates unusual value relative to the normalized dispersion and night time fluctuation on $25^{\text {th }}$ June. The earthquakes on $21^{\text {st }}$ June and $30^{\text {th }}$ June are marked by vertical red dashed lines. 
on $31^{\text {st }}$ of May, $17^{\text {th }}$ of June, and $25^{\text {th }}$ of June for both non-normalized and normalized graph (Figure 8(a) and Figure 9(a)). The night time fluctuation increased and crossed the $2 \sigma$ line in non-normalized graph (Figure 8(b)), and simultaneously decreased to minimum (crossing $2 \sigma$ line) on $31^{\text {st }}$ of May and $17^{\text {th }}$ of June in normalized graph (Figure 9(b)). From Figure 8(c), we can see that night time dispersion decreased in non-normalized graph and, as in the Figure 10(c), correspondingly increases in normalized graph on $31^{\text {st }}$ of May and $17^{\text {th }}$ of June crossing the $2 \sigma$ line. In Figure $8(\mathrm{c})$, we find the night time dispersion relatively less anomalous on $25^{\text {th }}$ June as only a small decrease(shown by green filled column), which didn't cross the $2 \sigma$ line, was seen, while the corresponding trend and night time fluctuation value exceed the $2 \sigma$ lines on the same day. Likewise, the normalized night time fluctuation on $25^{\text {th }}$ of June (Figure 9(b)) was less anomalous (shown by green filled column) when the corresponding normalized trend and night time dispersion crossed $2 \sigma$ lines on the same day.

In brief, the night time fluctuation crosses the $2 \sigma$ lines on $31^{\text {st }}$ of May, $17^{\text {th }}$ of June and $25^{\text {th }}$ of June and simultaneously the trend decreases abruptly even crossing $2 \sigma$ line. Not only this, the night time dispersion also decreases crossing $2 \sigma$ lines except on $25^{\text {th }}$ of June where it only decreases and therefore, the results were as per our expectation. Since EQ-I was not strong in magnitude; it is very unlikely that it perturbed the ionosphere 20 days before, on $31^{\text {st }}$ May. The Kp index was relatively high on $31^{\text {st }}$ May which explains the geomagnetic influences as the reason for the perturbation. Similarly, other factors like CG flashes, which have not been analyzed in this paper, could have also led to this unexpected variation. However, the anomaly seen on $17^{\text {th }}$ of June, which occurred4 days before EQ-1and anomaly seen on $25^{\text {th }}$ of June, which occurred 5 days prior to EQ-2, could be the precursor of those earthquakes.

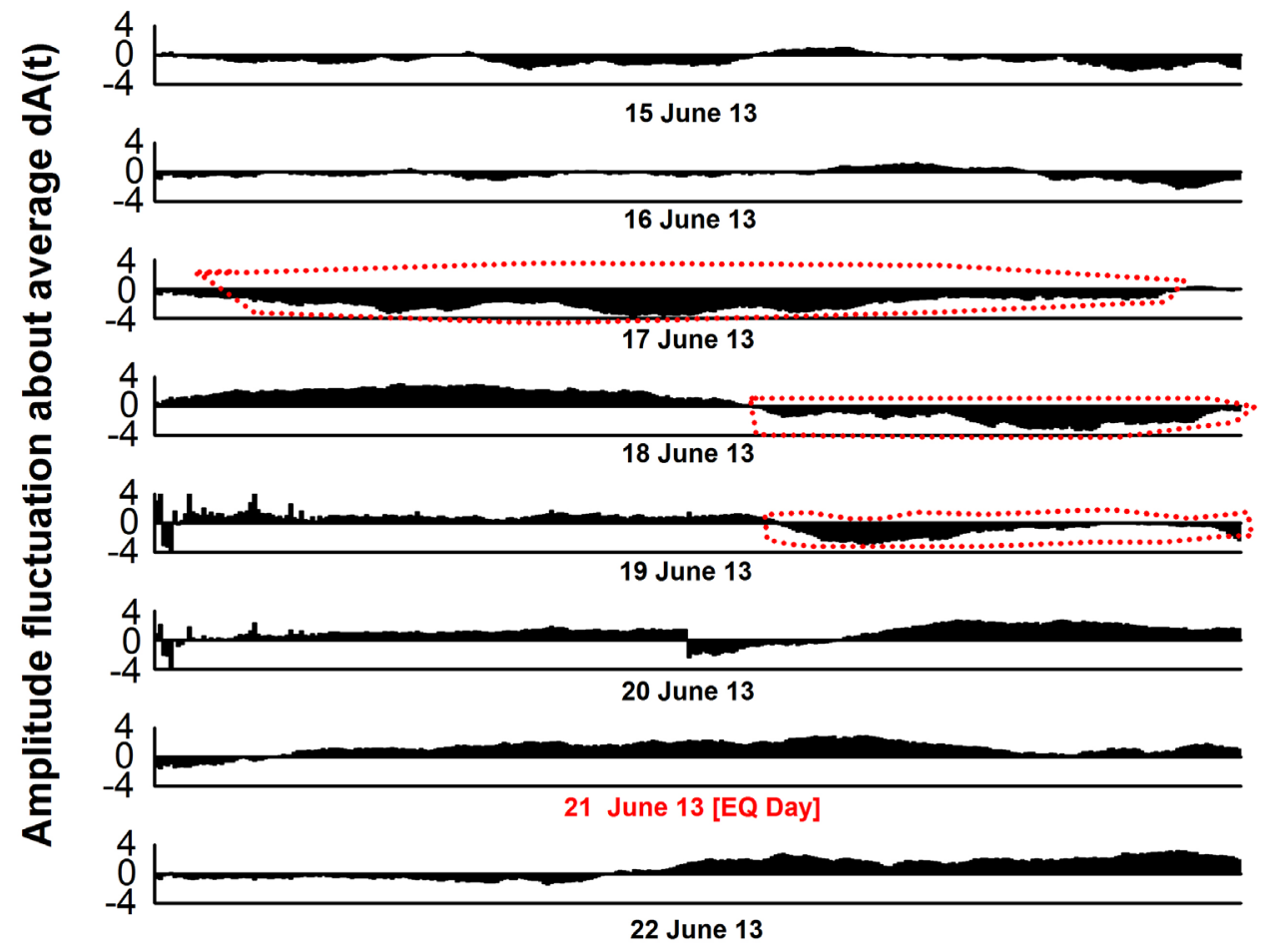

Hours for the Night time

Figure 10. Fluctuations in night time amplitude during the period of $15-22$ June 2013. The red dotted eclipses shows the condition of $d(A)<0$ prior to the earthquake day. The earthquake day has been marked in red letter on the $\mathrm{x}$-axis. The night time fluctuation unusually decreased 2 - 4 days prior to EQ-1 of $21^{\text {st }}$ June. i.e., on 17,18 and 19 June. 
Night time signal fluctuations were analyzed to examine if any changes occur in night time signal fluctuation $[2,3,15,19]$. We determined the values of $d(A)$ for night time, in the same way as mentioned in section 3 (Methods of Analysis), for the period of $15^{\text {th }}-25^{\text {th }}$ June (Figure 10). The solid horizontal line $(y=0$ line $)$ is the average night time amplitude and the values of the night time fluctuations in different times of a day were plotted. While analyzing, we were more concerned with $d(A)<0$ because the average night time amplitude were found to decrease around the days of earthquake $[14,17]$. The night time fluctuation decreased 2 - 4 days before EQ-1, starting from 17 June through 19 June, as shown by the red dotted eclipses in Figure 10. Thus, changes in night time fluctuations also seems likely to indicate the upcoming seismic activity.

\section{GEOMAGNETIC AND SOLAR ACTIVITIES}

In order to verify that the anomalies that we observed were result of seismo-ionospheric event (EQ) and not due to the geomagnetic storms, auroral activities or other geomagnetic activities we plotted the graph of Disturbance Storm-Time (Dst) index, AuroralElectrojet (AE) index and Kp index for the months May and June. We extracted the required data from http://omniweb.gsfc.nasa.gov/form/dx1.htmland confirmed them from http://wdc.kugi.kyoto-u.ac.jp/. We then evaluated if the days of anomalies (the blue dashed lines) coincides with the days having high geomagnetic activities with help of Figure 11 and Figure 12.

The blue dashed line passes through $3^{\text {rd }}$ of May, the anomalous day of the month of May. SST and DLDT showed unusual shift on this day. There were no significant rise in values of AE and Kp index and
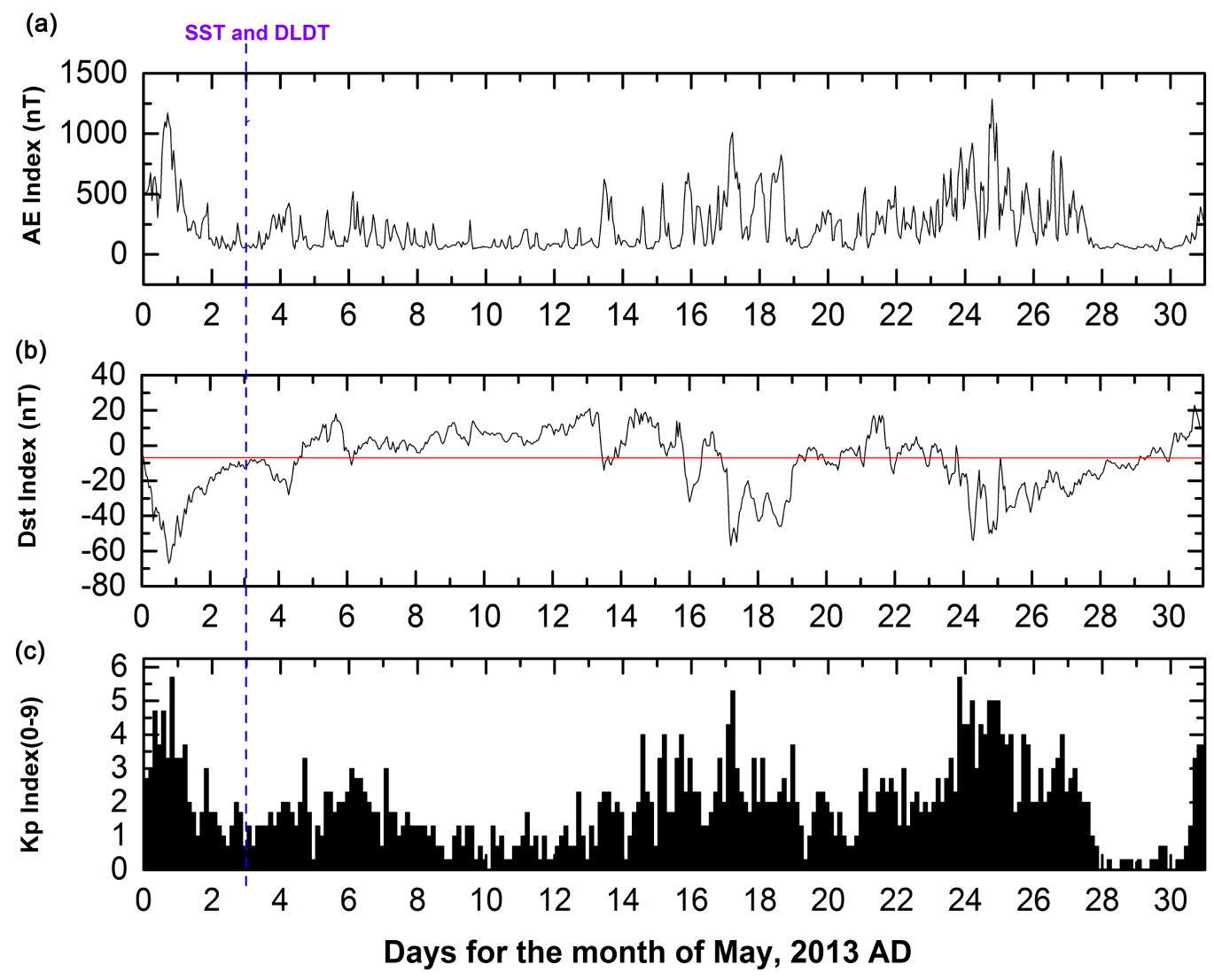

Figure 11. Variations in the (a) AE index, (b) Dst index, and (c) Kp index for the month of May. Blue dashed lines pass through anomalous days of May, 2013. On $3^{\text {rd }}$ May, SST and DLDT showed anomalies. 


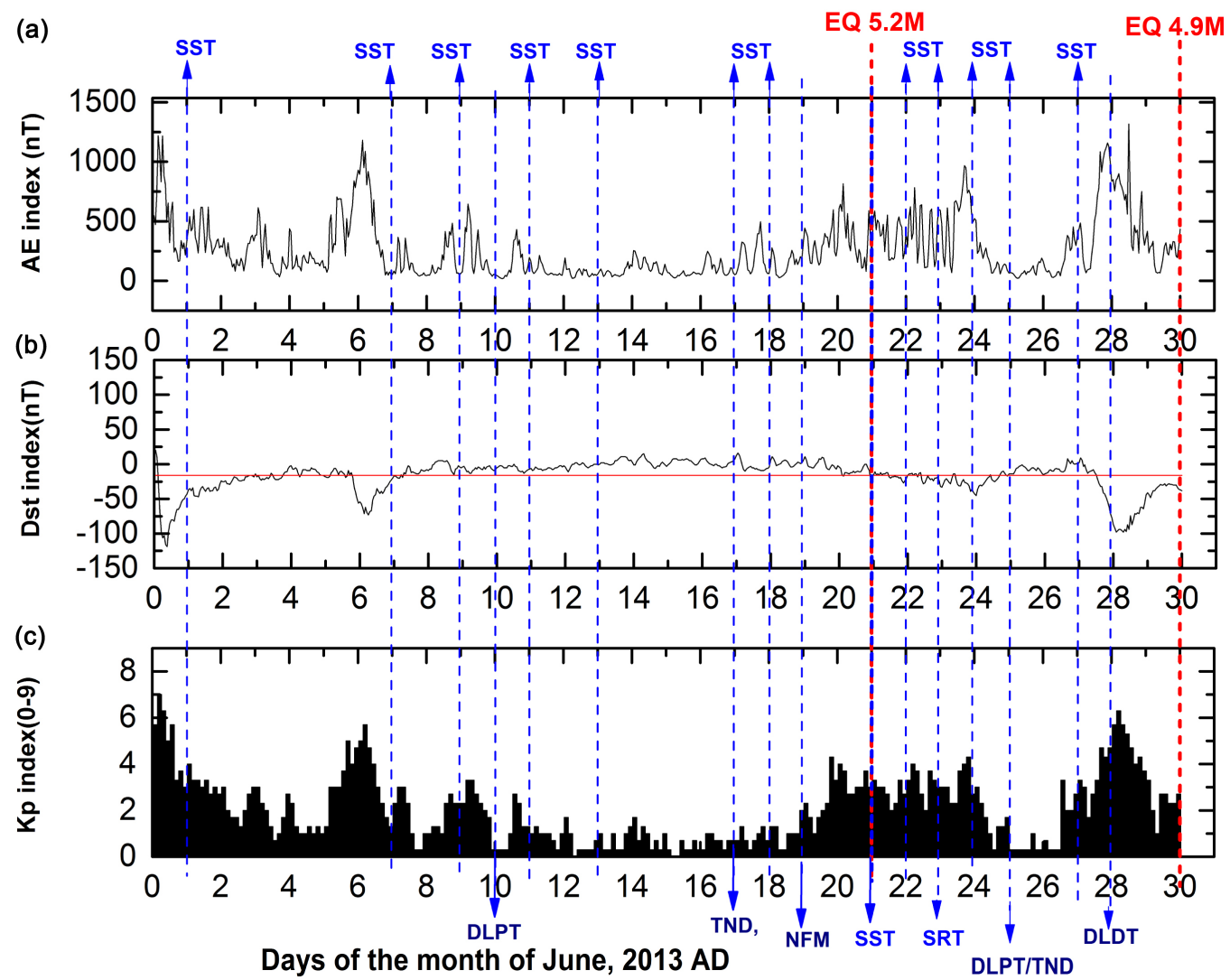

Figure 12. Variations in the (a) AE index, (b) Dst index, and (c) Kp index for the month of June. Blue dashed lines pass through the anomalous days of June, 2013. The terms in blue represent the parameters that were anomalous on the corresponding days. TND and NFM stand for trend and night time fluctuation method respectively.

no significant fall in Dst index on the day of anomaly (Figure 11). So, it lends support to our assumption that the anomalous variation on $3^{\text {rd }}$ May was due to various earthquakes occurring in the month of May i.e., $4^{\text {th }}$ and $8^{\text {th }}$ of May (Table 1). We also saw that on $31^{\text {st }}$ May, when the anomalies on trend, night time dispersion and night time fluctuations were seen, value for AE and Dst index was normal but value of Kp index was relatively high. This clarifies that the perturbations on $31^{\text {st }}$ of May was due to the effect of geomagnetic storms.

Similarly, no rise in $\mathrm{AE}$ and $\mathrm{Kp}$ index and no fall in Dst index were seen on anomalous days of the month of June as shown in Figure 12, except for $24^{\text {th }}$ of June where AE index and $\mathrm{Kp}$ index have greater value as compared to other anomalous days. Thus, most of the disturbances in VLF signals that caused led to anomalies in the parameters we used for analysis were due the seismic activities and their effect on the ionosphere before the earthquake.

The solar activities like solar flares, coronal mass ejection, solar cycles, etc., can also affect the ionosphere and cause unwanted disturbances in VLF/LF amplitude. Hence, to check whether the observed anomalies were due to different solar activities, we plotted the graphs of Bz (sigma), sunspot numbers, and solar index 10.7 (it provides climatology of solar activity over different solar cycles).

Blue dashes lines passing through the anomalous days have been given in Figure 13 and Figure 14. The terms in blue at the top and bottom of the graph show the corresponding parameters that were found anomalous. We found that $\mathrm{Bz}$ was normal for all anomalous day in May but was relatively higher on $31^{\text {st }}$ 


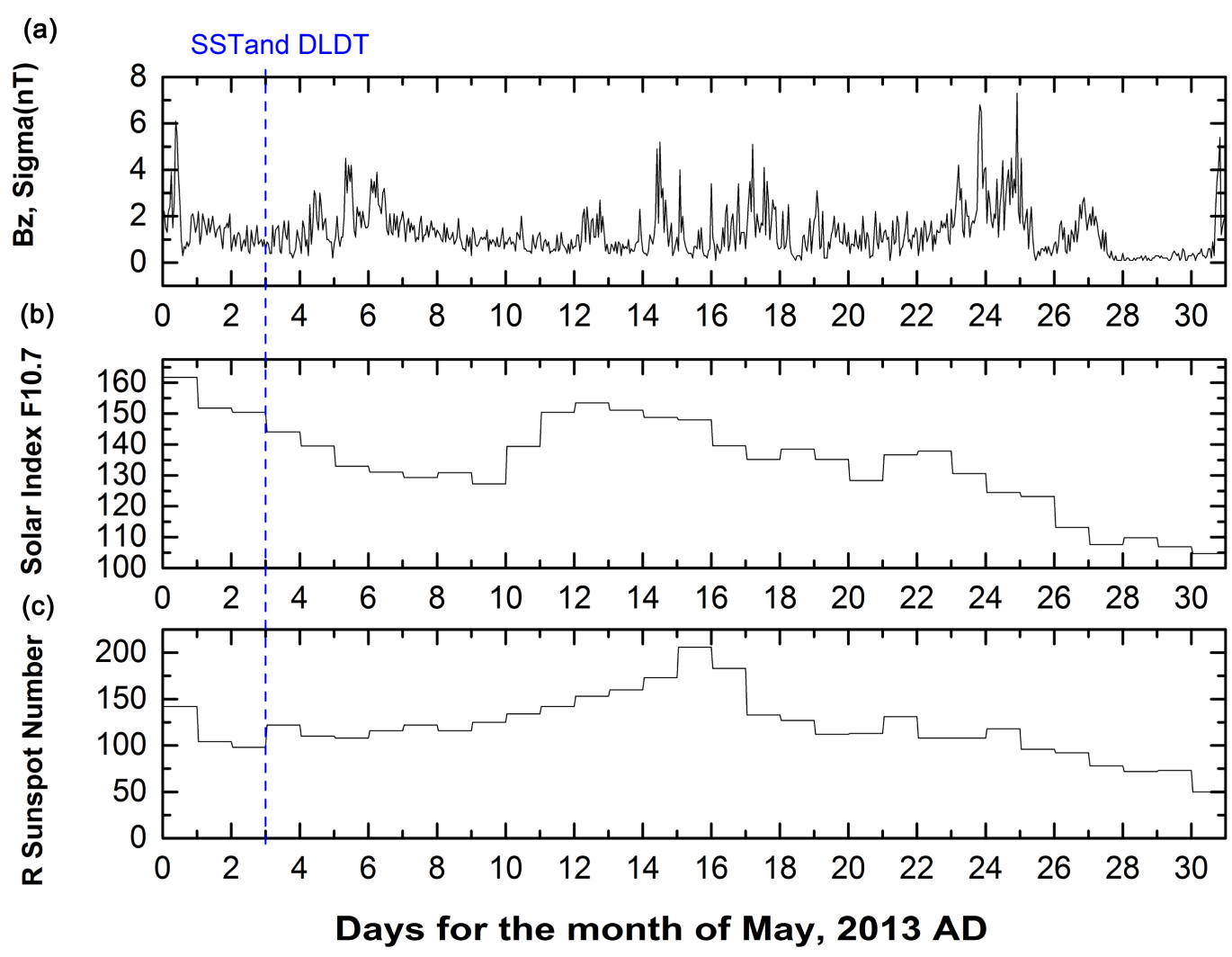

Figure 13. Variations in the (a) Bz (sigma), (b) solar index F10.7, and (c) sunspot number for the month of May. Blue dashed lines pass through anomalous days of May, 2013. On $3^{\text {rd }}$ May SST and DLDT show anomalies.

May, the day in which trend, night time dispersion, and night time fluctuation were unexpectedly anomalous, (Figure 13(a)). The solar index F10.7 was relatively higher on $3^{\text {rd }}$ May, the day in which anomaly in SST and DLDT was seen (Figure 13(b)). Thus, we doubt that the anomaly on $3^{\text {rd }}$ might also be affected by solar activities along with seismo-ionospheric effects.

For the month of June, we found that Bz sigma was relatively high on $1^{\text {st }}$ and $27^{\text {th }}$ of June among the anomalous days of June as shown in Figure 14(a). The solar index F10.7 and sunspot number was relatively high on $17^{\text {th }}, 18^{\text {th }}, 21^{\text {st }}, 22^{\text {nd }}$, and $23^{\text {rd }}$ of June as presented in Figure $14(\mathrm{~b})$ and Figure $14(\mathrm{c})$.

Among the large number of anomalies we noted, few anomalies seem to suffer effects of geomagnetic or solar activities. So in these days, the perturbations might have occurred as a combined effect of seismic effects and the geomagnetic and/or solar effects. All the other anomalies (on $3^{\text {rd }}, 7^{\text {th }}, 9^{\text {th }}, 10^{\text {th }}, 11^{\text {th }}, 13^{\text {th }}, 25^{\text {th }}$, and $28^{\text {th }}$ ) were caused by some other factor than geomagnetic or solar activities. This can be confirmed from the Figures 11-14, as the values of all the indices that we used to measure geomagnetic and solar activities were normal in many anomalous days of the month of June. Thus, the perturbations on the rest of the anomalous days can be said to be caused by the various seismicactivities, which influenced the sub-ionospheric layer, before the earthquake was felt. Thus, it can be concluded that various shifts in terminator times and changes in night time fluctuation, trend, night time dispersion, and average night time amplitudes that occur prior to the earthquake are the possible precursors to the earthquake.

\section{10 INTERNATIONAL QUIETEST DAYS (Q1-Q10) AND 5 INTERNATIONAL MOST DISTURBED DAYS (D1-D5)}

International disturbed days are the days in which maximum geomagnetic variations takes place. 
Based on the table above, only $7^{\text {th }}$ of June, among the anomalous days, was international disturbed day. However, among the days after $16^{\text {th }}$ June, which we are more concerned with, none of the days are international disturbed days. This data also helps to support our assertion that the anomalies on other days were no due to geomagnetic activities.

We referred to the site http://www.ga.gov.au/oracle/geomag/iqd_form.jsp for getting the information about international quiet and disturbed days and confirmed from http://wdc.kugi.kyoto-u.ac.jp/qddays/. Following Table 2 shows the corresponding days for the month of May and June, 2013.

\section{CONCLUSIONS}

On analyzing the VLF/LF amplitude data of May and June 2013, many unusual perturbations were observed especially in the month of June, the month in which the Tuscany earthquake took place. Following conclusions were drawn from this study.

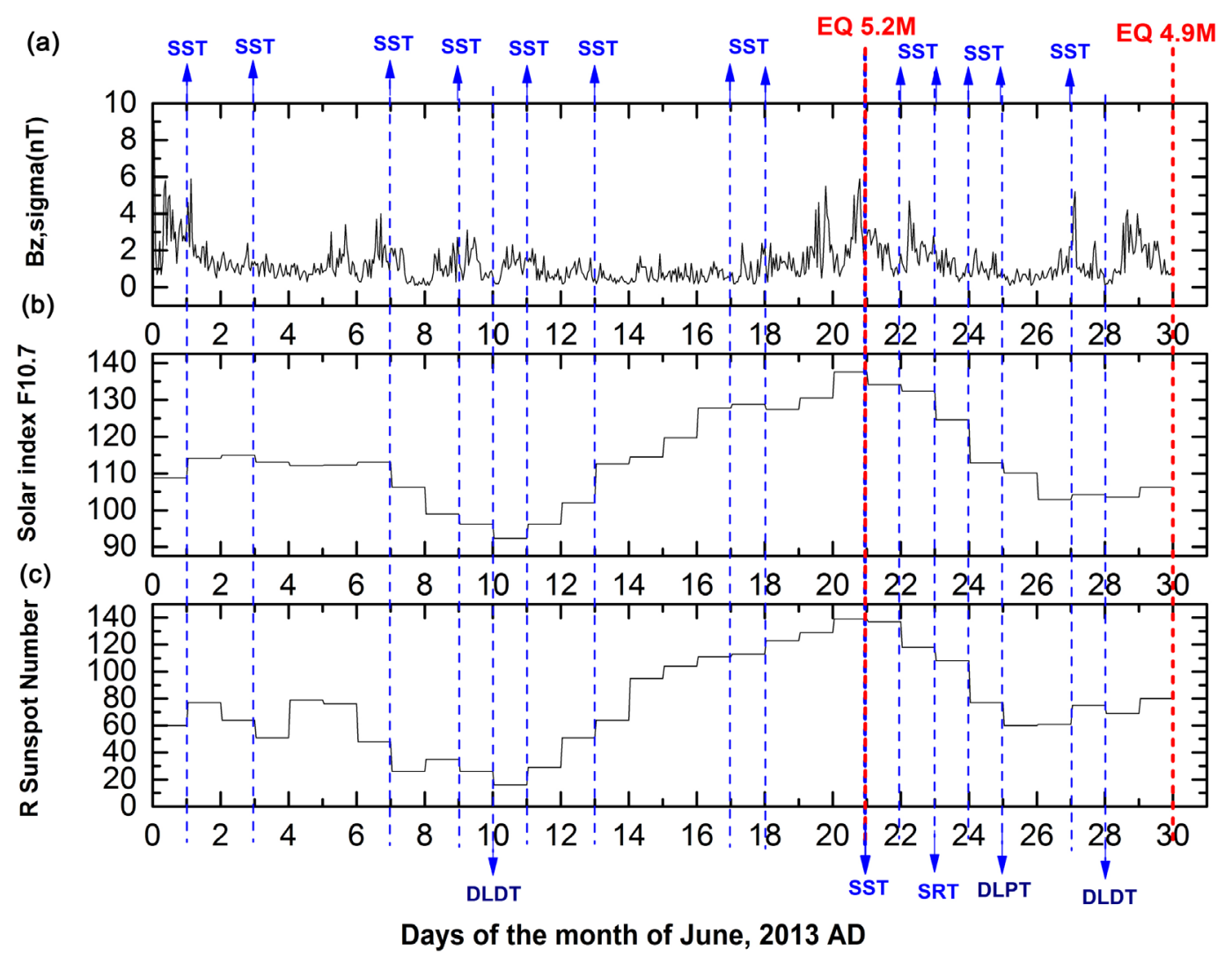

Figure 14. Variations in the (a) Bz (sigma), (b) solar index F10.7, and (c) sunspot number for the month of June. Blue dashed lines pass through the anomalous days of June, 2013. The terms in blue represent the parameters that were anomalous on the corresponding days.

Table 2. Table showing international disturbed and quiet days for the month of May and June.

\begin{tabular}{ccccccccccccccccc}
\hline Month & Year & Q1 & Q2 & Q3 & Q4 & Q5 & Q6 & Q7 & Q8 & Q9 & Q10 & D1 & D2 & D3 & D4 & D5 \\
\hline 2013 & MAY & 29 & 30 & 11 & 12 & 09 & 10 & 13 & 04 & 21 & 03 & 01 & 25 & 24 & 18 & 26 \\
2013 & JUNE & 16 & 26 & 17 & 13 & 14 & 18 & 12 & 15 & 19 & 05 & 01 & 29 & 07 & 06 & 28 \\
\hline
\end{tabular}


Table 3. Shows all anomalies in summary and reasoning behind their being clear precursor. Brown color inside brackets indicates anomalies before EQ-2 and after EQ-I. Rest of the anomalies (in black color) indicates anomalies before EQ-1 if they lie within a week's time; the ones more than 7 days before are precursors to other earthquakes of the month. The "Clear" Precursors are written in bold for easy recognition in the $3^{\text {rd }}$ Column. The $4^{\text {th }}$ Column states why the seen anomaly can't be regarded as a clear precursor.

\begin{tabular}{|c|c|c|c|}
\hline Method of Analysis & $\begin{array}{c}\text { Date of Anomaly } \\
\text { (Days before earthquake) }\end{array}$ & $\begin{array}{l}\text { Status of } \\
\text { Precursors }\end{array}$ & Remarks \\
\hline \multirow[t]{8}{*}{ SRT } & 23 June 2013 (7 days) & Unclear & $\begin{array}{l}\text { High solar F10.7 index } \\
\text { and sunspot number }\end{array}$ \\
\hline & 3 May 2013 & Unclear & $\begin{array}{l}\text { Much before the weak EQ M5.2 } \\
\text { Clear precursor to EQ's in May }\end{array}$ \\
\hline & 1 June 2013 & Unclear & $\begin{array}{l}\text { International Disturbed Day } \\
\text { High Bz index }\end{array}$ \\
\hline & 3 June 2013 & Unclear & Much before the weak EQ \\
\hline & 7 June 2013 (14 days) & Unclear & International Disturbed Day \\
\hline & 9 June 2013 (12 days) & Clear & \\
\hline & 11 June 2013 (10 days) & Clear & \\
\hline & 13 June 2013 (8 days) & Clear & \\
\hline \multirow[t]{7}{*}{ SST } & 17 June 2013 (4 days) & Unclear & $\begin{array}{l}\text { High solar index F10.7 } \\
\text { and sunspot number }\end{array}$ \\
\hline & 18 June 2013 (3 days) & Unclear & $\begin{array}{l}\text { High solar F10.7 index } \\
\text { and sunspot number }\end{array}$ \\
\hline & 21 June 2013 (9 days) & Unclear & $\begin{array}{l}\text { High solar F10.7 index } \\
\text { and sunspot number }\end{array}$ \\
\hline & 22 June 2013 (8 days) & Unclear & $\begin{array}{l}\text { High solar F10.7 index } \\
\text { and sunspot number }\end{array}$ \\
\hline & 23 June 2013 (7 days) & Unclear & $\begin{array}{l}\text { High solar F10.7 index } \\
\text { and sunspot number }\end{array}$ \\
\hline & 24 June 2013 (6 days) & Unclear & High Kp index and AE index \\
\hline & 27 June 2013 (3 days) & Unclear & High $\mathrm{Bz}$ index \\
\hline DLPT & 25 June 2013 (5 days) & Clear & \\
\hline
\end{tabular}




\begin{tabular}{cccc}
\hline DLDT & 3 May 2013 & Unclear & $\begin{array}{c}\text { High AE index and } \\
\text { solar F10.7 index }\end{array}$ \\
& 10 June 2013 (11 days) & Clear & \\
28 June 2013 (2 days) & Unclear & International Disturbed Day \\
$\begin{array}{c}\text { Nighttime fluctuation } \\
\text { method }\end{array}$ & 19 June 2013 (2 days) & Clear & \\
$\begin{array}{c}\text { Trend, dispersion and } \\
\text { nighttime fluctuation }\end{array}$ & 17 June 2013 (4 days) & Clear & Huch before the weak EQ \\
& 25 June 2013 (5 days) & Clear & \\
\hline
\end{tabular}

We have taken the considered the anomalous days within 2 weeks' time while making this table. "Clear" precursors in Table 3 indicate the anomalies that were filtered out after considering the effects of solar and geomagnetic effects. "Unclear" precursors mentioned in table must have one of the following possibilities 1) Combined effect of seismic activities before the earthquake tremor and the particular high geomagnetic or solar activities. 2) Complete effect of high geomagnetic or solar activities. 3) Complete effect of seismic events. Most of the "unclear" precursors in our case might be combined effect. It is not necessary that high geomagnetic or solar activity always affects the ionosphere severely. However, to be on safe side, we removed all the possible effects by geomagnetic or solar activities to confirm the anomalies to be clear precursors. Moreover, one can notice most of the anomalies are seen in terminator times and most of clear precursors are seen in nighttime fluctuation method. The anomalies before 7 days of earthquake have been considered the precursor to other earthquakes of the month as mentioned in Section 4.1.

Thus, VLF/LF signals were perturbed few days about 2 weeks before the day of earthquake. Hence, these aforementioned anomalies can be considered possible precursors to the earthquake. We assume that the shortness of propagation path, nearness of epicenter to propagation path, and shallow focal depth to be the reasons that the perturbations in VLF signal were easily received and eventually recorded by the Kiel Long Wave Monitor even when the earthquake was not strong enough.

\section{ACKNOWLEDGEMENTS}

We express our gratitude to Peter Wilhelm Schnoor, head of Kiel Long Wave Monitor, for helping us with the data without which this study would have been next to impossible.

\section{REFERENCES}

1. Hayakawa, M., Molchanov, O.A., Ondoh, T. and Kawai, E. (1996) On the Precursory Signature of Kobe Earthquake in Sub-Ionospheric VLF/LF Propagation. Communications Research Laboratory, 43, 169-180.

2. Hayakawa, M., et al. (2011) Ionospheric Perturbations in Possible Association with the 2010 Haiti Earthquake as Based on Medium-Distance Sub-Ionospheric VLF/LF Propagation Data. Natural Hazards and Earth System Sciences, 11, 513-518. https://doi.org/10.5194/nhess-11-513-2011

3. Maekawa, S., Horie, T., Yamauchi, T., Sawaya, T., Ishikawa, M., Hayakawa, M. and Sasaki, H. (2006) A Statistical Study on the Effect of Earthquakes on the Ionosphere Based on the Sub-Ionospheric LF Propagation Data in 
Japan. Annals of Geophysics, 24, 2219-2225. https://doi.org/10.5194/angeo-24-2219-2006

4. Ray, S., Chakrabarti, S.K. and Sasmal, S. (2012) Precursory Effects in the Night Time VLF Signal Amplitude for the 18th January, 2011 Pakistan Earthquake. Indian Journal of Physics, 86, 85-88.

https://doi.org/10.1007/s12648-012-0014-5

5. Hayakawa, M. (2007) VLF/LF/LF Radio Sounding of Ionospheric Perturbations Associated with Earthquakes. Sensors, 7, 1141-1158. https://doi.org/10.3390/s7071141

6. Molchanov, O.A. and Hayakawa, M. (1998) Sub-Ionospheric VLF/LF Signal Perturbations Possibly Related to Earthquakes. Journal of Geophysical Research: Space Physics, 103, 17489-17504.

7. Molchanov, O.A., et al. (1998) Precursory Effects in the Sub-Ionospheric VLF/LF Signals for the Kobe Earthquake. Physics of the Earth and Planetary Interiors, 105, 239-248. https://doi.org/10.1016/S0031-9201(97)00095-2

8. Nagao, T., et al. (2002) Electromagnetic Anomalies Associated with 1995 Kobe Earthquake. Journal of Geodynamics, 33, 401-411. https://doi.org/10.1016/S0264-3707(02)00004-2

9. Ray, S. and Sandip, K.C. (2013) A Study of the Behavior of the Terminator Time Shifts using Multiple VLF Propagation Paths during the Pakistan Earthquake $(\mathrm{M}=7.2)$ of 18 January 2011. Natural Hazards and Earth System Sciences, 13, 1501-1506. https://doi.org/10.5194/nhess-13-1501-2013

10. Rozhnoi, A., et al. (2009) Anomalies in VLF/LF Radio Signals Prior the Abruzzo Earthquake $(\mathrm{M}=6.3)$ on 6 April 2009. Natural Hazards and Earth System Sciences, 9, 1727-1732.

https://doi.org/10.5194/nhess-9-1727-2009

11. Sasmal, S. and Chakrabarti, S.K. (2009) Ionosperic Anomaly Due to Seismic Activities Part 1: Calibration of the VLF Signal of VTX $18.2 \mathrm{KHz}$ Station from Kolkata and Deviation during Seismic Events. Natural Hazards and Earth System Sciences, 9, 1403. https://doi.org/10.5194/nhess-9-1403-2009

12. Chakrabarti, S.K., Sasmal, S. and Chakrabarti, S. (2010) Ionospheric Anomaly Due to Seismic Activities Part 2: Evidence from D-Layer Preparation and Disappearance Times.

13. Hayakawa, M., et al. (2010) A Statistical Study on the Correlation between Lower Ionospheric Perturbations as Seen by Sub-Ionospheric VLF/LF/LF Propagation and Earthquakes. Journal of Geophysical Research: Space Physics, 115, A9. https://doi.org/10.1029/2009JA015143

14. Kandel, K.P., Khadka, B., Bhatta, K., et al. (2017) On Precursors to the Italy Earthquake M.6.2 using VLF/LF Signal of NSY (45.9 kHz) Received at Kiel Long Wave Monitor. Acta Geophysica.

15. Kasahara, Y., et al. (2010) The Ionospheric Perturbations Associated with Asian Earthquakes as Seen from the Sub-Ionospheric Propagation from NWC to Japanese Stations. Natural Hazards and Earth System Sciences, 10, 581-588. https://doi.org/10.5194/nhess-10-581-2010

16. Kumar, A., et al. (2013) Sub-Ionospheric VLF/LF Perturbations Observed at Low Latitude Associated with Earthquake from Indonesia Region. Journal of Atmospheric and Solar-Terrestrial Physics, 102, 71-80. https://doi.org/10.1016/j.jastp.2013.04.011

17. Rozhnoi, A., Solovieva, M.S., Molchanov, O.A. and Hayakawa, M. (2004) Middle Latitude LF (40 kHz) Phase Variations Associated with Earthquakes for Quiet and Disturbed Geomagnetic Conditions. Physics and Chemistry of the Earth, 29, 589-598. https://doi.org/10.1016/j.pce.2003.08.061

18. Hayakawa, M., et al. (2012) Possible Precursor to the March 11, 2011, Japan Earthquake: Ionospheric Perturbations as Seen by Sub-Ionospheric Very Low Frequency/Low Frequency Propagation. Annals of Geophysics, 55, 1.

19. Kasahara, Y., et al. (2008) On the Statistical Correlation between the Ionospheric Perturbations as Detected by 
Sub-Ionospheric VLF/LF/LF Propagation Anomalies and Earthquakes. Natural Hazards and Earth System Sciences, 8, 653-656. https://doi.org/10.5194/nhess-8-653-2008

20. Ray, S., et al. (2011) Ionospheric Anomaly due to Seismic Activities-III: Correlation between Night Time VLF/LF Amplitude Fluctuations and Effective Magnitudes of Earthquakes in Indian Sub-Continent. Natural Hazards and Earth System Science, 11, 2699-2704. https://doi.org/10.5194/nhess-11-2699-2011

21. Grimalsky, V.V., Hayakawa, M., Ivchenko, V.N., Rapoport, Y.G. and Zadorozhnii, V.I. (2003) Penetration of an Electrostatic Field from the Lithosphere into the Ionosphere and Its Effect on the D-Region before Earthquakes. Journal of Atmospheric and Solar-Terrestrial Physics, 65, 391-407.

https://doi.org/10.1016/S1364-6826(02)00341-3 